University of Nebraska - Lincoln

DigitalCommons@University of Nebraska - Lincoln

Faculty Publications, UNL Libraries

Libraries at University of Nebraska-Lincoln

May 1994

Focusing on Quality Reference Service

Tracy Bicknell-Holmes

University of Nebraska-Lincoln, tbicknel@gmail.com

Follow this and additional works at: https://digitalcommons.unl.edu/libraryscience

Part of the Library and Information Science Commons

Bicknell-Holmes, Tracy, "Focusing on Quality Reference Service" (1994). Faculty Publications, UNL Libraries. 159.

https://digitalcommons.unl.edu/libraryscience/159

This Article is brought to you for free and open access by the Libraries at University of Nebraska-Lincoln at DigitalCommons@University of Nebraska - Lincoln. It has been accepted for inclusion in Faculty Publications, UNL Libraries by an authorized administrator of DigitalCommons@University of Nebraska - Lincoln. 


\title{
Focusing on Quality Reference Service
}

\author{
by Tracy Bicknell
}

Literature from the service industries consistently defines quality service in terms of the user, whereas library literature rarely defines quality reference service other than in simple quantitative terms. Quality reference service meets user needs and expectations through appropriate staff behavior and communication skills, a user friendly environment, and suitable levels of staff morale and workload.

Tracy Bicknell is the Business Liaison Librarian, 216N Love Library, University of Nebraska-Lincoln, Lincoln, NE 68588-0410. tracyb@unllib.unl.edu
The majority of published research that has assessed library reference service performance in the last 25 years has measured the accuracy of answers to factual and bibliographic questions. ${ }^{1}$ Whitlatch, for one, questions the assumption that accurate fact provision alone is a key indicator of reference performance or service quality. ${ }^{2}$ The accuracy of the answers users receive should be a concern, but accuracy may not be the sole indicator of quality service.

Another common practice in the assessment of reference services has been to tabulate the number of questions received at the reference desk, assuming that a continuous increase in the number of questions indicates good service. However, as Hansel points out, "staff will freely admit that their reference statistics are inaccurate." She speculates that "if a reference staff answers a large number of questions, that could mean simply that the library is so incomprehensibly organized that users cannot find anything on their own." 3

Few studies of quality reference service have defined or identified the various components of "quality" reference service other than in terms of the accuracy of answers to factual and bibliographic questions. Aluri's article on improving reference service using continuous quality improvement methods is a good example of a study that defines reference service in broader terms. ${ }^{4}$ In the business literature, quality service is unanimously defined as meeting customer needs and expectations; in addition, the environment in which the service transaction takes place, staff behaviors, and staff morale are noted as important elements of quality service.

By combining some components found in library literature with a business service definition of quality, four aspects of service interaction have significant implica- tions to assessing the quality of reference work:

- User needs and expectations,

- Staff behaviors and communication skills,

- The reference environment, and

- Staff morale and workload. ${ }^{5}$

This article describes each aspect of quality service and suggests ways of assessing it in order to develop a quality reference service program.

User Needs and Expectations

It has been argued that librarians are not very adept at learning to know and understand the real needs of consumers of information. For example, Campbell states that "we expect our users to take information on our terms, and we interpret their use as vindication of the value of our libraries." He further states that librarians should "focus on what the consumer would like and how we can deliver it rather than on training the consumer to adapt to what the library offers." ${ }^{\text {Like- }}$ wise, business articles on quality service repeatedly stress that the focus of any quality service program should be on the customer's needs and expectations, and on reducing the perceived gap between those needs and expectations and the actual service received. As Inglis notes, when businesses do not ask customers about their needs, gaps in service quality occur. A company's perception of what customers need and what constitutes quality may not agree with the reality of its customers' expectations. ${ }^{7}$ Inglis' observations may be applied to studies which seek to measure the accuracy of reference work. Many reference studies have assumed that a user's primary need is to receive an accurate answer, but very few studies have attempted to find out if that is truly a user's primary need. For example, Durrance found that 90 percent of participants of an 
unobtrusive study would not ask another question of a staff member who had seemed unfriendly, uninterested or made them feel uncomfortable, even if they had received the correct answer. ${ }^{8}$

Some librarians are changing the configuration of staffing on the reference desk without first identifying user needs. This is another example of librarians making assumptions as to what constitutes quality service. There may, indeed, be new ways to conduct reference work that are more efficient, cost effective, and beneficial to users. However, making changes without first trying to discover user needs will not necessarily increase the quality of reference service. ${ }^{9}$ Librarians interested in quality reference service, must identify user needs, not make assumptions about those needs.

\section{"Many reference studies have assumed that a user's primary need is to receive an accurate answer, but very few studies have attempted to find out if that is truly a user's primary need."}

Surveys attempting to measure satisfaction with reference service have often simply asked if the user was or was not satisfied, and may not have tried to gauge the reasons for the answer. If a simple satisfaction survey comes back positive, it could mean that the user's original expectations of the service quality had been very low. In the business literature, HaywoodFarmer, Alleyne, Duffus, and Downing note that "in quality control terms, not only is the target [customer satisfaction] fuzzy and moving, but it is camouflaged as well" because customers themselves have difficulty identifying and describing their needs, and their needs keep changing. Yet, the authors note that some peripheral services are more important to customer satisfaction than core services, and "it takes 12 acceptable or superior quality attributes to overcome the negative impact of a single inferior one."10 Additionally, Max Larson, Executive Vice President and Senior Research Analyst with Gallup, describes the "Clean Bathroom Syndrome" for restaurants. Customers often state location, food, or atmosphere as reasons why they frequent a restaurant, but when asked why they do not visit other restaurants periph- eral aspects such as whether the bathrooms were clean on their last visit are listed. ${ }^{11}$ Any program of quality reference service should attempt not only to weigh user satisfaction but to go beyond simple measures of satisfaction and attempt to gauge the causes of both positive and negative levels of satisfaction.

Further complicating the issue of assessing user satisfaction is the finding that various attributes of library users have an impact on the quality of reference service. In assessing attributes, Kuhlthau identifies six stages of the Information Search Process (ISP) through which users progress when seeking information: initiation, selection, exploration, formation, collection, and presentation. ${ }^{12}$ At each stage of the process user information needs and states of mind vary. For example, in the beginning stages of an information search, students may need to talk to a librarian to get ideas or encouragement, or to overcome their fear of libraries, not necessarily to get a specific answer or list of sources to use. The students' perception of quality service at this stage will be impacted by how comfortable the librarian makes them feel. In brief, the ISP stages and the sophistication of the user have a direct impact on the perceived quality of reference service, and illustrate that user needs may require more than a single accurate answer.

Measuring User Needs and Expectation. Some authors argue against the use of subjective measures of reference performance, such as user opinions, on the grounds that users are not competent to render valid evaluations of library services. However, D'Elia and Walsh see subjective measures by users to be an effective complement to objective approaches to evaluating library service. ${ }^{13}$ Additionally, consumer behavior research has illustrated that both positive and negative word-of-mouth advertising can have a significant impact on the attitudes and behaviors of users and, in fact, the opinions of friends and relatives may be more important than any other factor on whether or not a person uses the library. ${ }^{14}$ Therefore, discovering what users may be telling other users and nonusers about the library's services is important to the evaluation of quality reference service, and subjective measures of user needs and expectations may be the most cost-effective way to investigate user opinions about reference service.

Methods. Some effective ways to measure user needs and expectations include:
- Develop a user survey. Cronin and Taylor have created a survey with a 17 point attitudinal scale which attempts to measure reasons for satisfaction/dissatisfaction by having users evaluate performance measures and rate the importance of the measures. ${ }^{15}$ This scale would be an excellent place to begin in developing a library user satisfaction scale.

- Persuade a professor teaching a class on consumer behavior or market research to have the class develop a library user profile as a class project.

- Interview strategic users.

- Observe interaction and user behavior at the reference desk and within the reference area.

- Conduct focus group sessions to discuss reference service and the components of quality.

Each library should select an evaluation method based on available resources and local user characteristics. If possible, data should be gathered over time so that trends may be identified, and more than one method of assessment should be used so that a single method's individual biases may be reduced. Regardless of the method used, an effort should be made to relate satisfaction to expectations, delve into the causes of dissatisfaction and ask questions such as "would you recommend this service to a friend?"16 Each user group is unique. Therefore, individual surveys should be tailored to assess accurately the needs of one group, rather than using one survey for all groups of users. ${ }^{17}$ Finally, a user investigation should target core users, rather than fringe groups or nonusers. ${ }^{18}$ This is not only more efficient, but repeated studies have shown that people do not generally think of the library as a source of information and nonusers may not be able to articulate clearly the reasons why they do not use the library. ${ }^{19}$ If reference service is improved to the satisfaction of core users, positive word-of-mouth advertising ought eventually to result in an increased user population.

\section{Librarian Behaviors and \\ Communication Skills}

Behaviors and communication skills of reference librarians have a major impact on the reference transaction. Although studies on the accuracy of answers to factual and bibliographic questions may not be a good measure of the overall quality of reference service, three separate accuracy studies describe the behavioral aspects of the reference process which have a signif- 
icant impact on the success of the reference interview. ${ }^{20}$ If the librarian probed for the actual information need, seemed interested and attentive, made the patron feel at ease, and asked a follow-up question to make sure the patron found what was needed, the interaction was more likely to be a success. Of these four behaviors, asking a follow-up question was noted as the most important aspect of any reference transaction. Further, Bunge and Murfin found that successful librarians displayed greater sensitivity to communication problems than less successful librarians. ${ }^{21}$

Each of the behaviors described above has an impact on the quality of reference transactions. The behaviors are observable, can be taught, and are generally within a reference librarian's control.

Assessing Behaviors and Communication Skills. Numerous studies have proposed ways to measure communication skills and behaviors. Some effective strategies include:

- A customized skills assessment (CSA) which is developed in-house and begins by identifying the behaviors and skills needed for successful service interactions. 22

- A peer evaluation process using a fivepoint scale and general criteria for review, which stresses that reviews should be focused on improving performance and not be related to promotion and salary decisions. ${ }^{23}$

- An evaluation process focused on the objectives of the reference process, the content of the reference interview, the form of the interview, and the end product. $^{24}$

- A "Behaviorally Anchored Rating Scale" (BRS) in relation to Management by Objectives (MBO) where staff members set goals to improve their performance. ${ }^{25}$

- A Reference Transaction Assessment Instrument (RTAI) for evaluating reference service. ${ }^{26}$

- The Attributive Theory of Quality and a panel of experts to evaluate reference transactions. ${ }^{27}$

Combining two or more evaluation techniques may be most successful for assessing communication skills and behaviors. Using more than one technique may compensate for any bias inherent in any one method. In addition, regular training should occur on successful communication skills and behaviors. Temple University's "customer care training" pro- gram for its public service staff may serve as an example. ${ }^{28}$ Staff evaluation and training in behaviors and communication skills identified as contributing to successful interactions are crucial to a quality reference service program.

\section{The Environment}

Reference transactions do not occur in a vacuum, but in an environment centered around a desk or counter, which has basically remained unchanged since the emergence of the concept of reference work. The environment can have a significant impact on user satisfaction and the success of the reference process.

"Although many library
buildings are not optimally
designed, librarians should take
cues from the business
literature and evaluate the
environment from a service
perspective."

Although librarians consider themselves to be professionals, Durrance notes that the library environment may not convey a professional image. Often signage identifying service points, professionals, functions or directions is poor or nonexistent, creating confusion or uncertainty for users. ${ }^{29}$

Service Environment. Bitner puts the service environment in perspective by recognizing that people use extrinsic cues to infer quality about a service and the people who work there. In addition, she outlines three composite dimensions as particularly relevant to service quality: ambient conditions such as temperature and lighting, spatial layout and functionality, and symbols, signs, and artifacts. Even subtle changes can greatly enhance or detract from user satisfaction. Furthermore, service designs should follow a continuum from self service where users help themselves, such as an open stacks area, to remote service where only staff are present, such as technical services. Particular attention is needed at service points where staff and users interact and a user's opinions and expectations are formed.$^{30} \mathrm{~A}$ reference desk, as a service point, falls in the middle of Bitner's service continuum.

Evaluating the Environment. Although many library buildings are not optimally designed, librarians should take cues from the business literature and eval- uate the environment from a service perspective. Because signage may be a relatively inexpensive way to remedy some of the problems inherent in a building, some possible techniques for discovering problems with signage follow:

- Survey staff members about the most common directional questions received at the reference desk. If staff at a reference desk receive numerous directional questions, perhaps this is a signal that signage is poor and should be revised.

- Evaluate the image the current signs convey. Begin at the front entrance to the library. Is it clear that users who do not know where to start may ask questions at the reference desk? Do the signs convey library jargon? Do they identify the functions of each area of the library? Are the signs worded to encourage questions, or do they cause further confusion? A panel of users could help evaluate the signage and reference area layout and give suggestions.

- Compare the library's signage with that of a local hospital, fast food restaurant, or grocery store. What aspects of the signage in these service areas are adaptable or exceptionally helpful?

- Evaluate the philosophy of service at each point in the reference area. If users are encouraged to help themselves, does the signage and layout encourage self service?

Every quality reference program should include efforts to arrange layouts for ease of use and provide clearly visible signage with users in mind. If possible, users should be asked for input on the reference environment.

\section{Morale and Work Overload}

There has been some discussion on low morale among reference librarians and the possible impact that this may have on quality reference. Bunge blames low morale on the increasing range and complexity of information sources coupled with more demanding clients and pressures to be professionally active. ${ }^{31}$ Miller believes that libraries are currently in the position of proclaiming universally excellent service for everyone while serving no one especially well. The result is low morale among librarians. ${ }^{32}$ Miller and Bunge conclude that low morale is widespread and causes poor service quality.

Lowenthal tried to measure the impact of low morale on reference service quality in seven public libraries. He concluded that high levels of negative emotional 
states may contribute to lower job satisfaction, commitment, and productivity, and may have a significant impact on quality reference work. ${ }^{33}$

Most reference librarians can probably remember times when it was difficult to concentrate at the reference desk because of a project with an imminent deadline. Many may even remember times when the workload was so heavy that the desk shift seemed like a chore. If morale and unrealistic workloads do have a significant impact on behavior and reference work, these aspects should be addressed in a quality service program.

\section{"Each quality reference program should address the issues of morale and workload. Creating avenues for continuous training and problem solving should relieve some of the stress of a constantly changing environment."}

Evaluating Morale and Workload. If morale is affected by factors such as 'workload and the addition of more and more new information sources, then measures for evaluating morale and workload should be considered. One strategy is to replicate Lowenthal's test, adding questions to the instrument about why morale is at the level recorded so that improvements can be made if necessary. ${ }^{34}$

A variety of strategies can be implemented to help reference librarians cope with an increasing workload:

- Prioritize the services offered by the reference staff. Grover suggests assessing user needs and using a chart outlining the "societal functions of libraries" to classify each service as passive (collections are available), reactive (service is rendered on request), or assertive (a user need is identified and a service customized to serve the need). ${ }^{35}$

- Develop a problem-solving process such as Fredenburg's, which records and tracks problems from their discovery to solution, and includes followup. ${ }^{36}$ Many libraries already have procedures for reporting problems or taking suggestions which may be the basis for developing such procedures. For example, many online catalogs have a suggestion box. Comments posted to the suggestion box should be recorded, routed to the appropriate person, investigated, solved if possible, and followed up to see if the solution worked.

- Record and route questions, comments, and complaints en masse occasionally. If patterns are noted, possible solutions should be suggested and implemented.

- Update librarians on new sources, review old sources, or demonstrate how to use new electronic sources via regular staff meetings.

- Provide written or online manuals explaining new sources or outlining common questions. If possible, search strategies and exercises should be included. A manual might be particularly useful when a librarian or staff member is under stress or tired.

- Establish a daily information box, bulletin board, or online file for current questions that are difficult. This box/ board/file should be cleaned out regularly with only the most pertinent information remaining. Otherwise, staff who continually see the same notices will stop reviewing what has been posted. Useful tidbits could be moved to a manual to be saved.

- Use listservs as a source of current information as many serve as question and answer forums. Difficult questions could be posted to a listserv for more global teamwork, and particularly useful notes on the listserv could be put into a manual or routed among staff members.

Each quality reference program should address the issues of morale and workload. Creating avenues for continuous training and problem solving should relieve some of the stress of a constantly changing environment.

\section{Conclusion}

In this age of accountability and tight budgets, librarians would do well to take some cues from the business world. If librarians offer quality reference service which is responsive to user needs, there is a potential for building a strong support base to argue for additional or continued support for the library. In addition, if librarians get to know users' needs and expectations, they will be better equipped to offer quality, efficient, cost-effective service with the funding and staff available.

Each library has its own unique clientele, building, and philosophy of service.
Thus, each library's program of quality reference service will have its own unique aspects. Regardless of site specific details, every quality reference program should focus on meeting user needs and expectations by enhancing staff behaviors and communication skills, by providing a user friendly reference environment, and by ensuring suitable levels staff morale and workload.

\section{Notes and References}

1. For a good summary of research on the accuracy of reference service see Kenneth D. Crews, "The Accuracy of Reference Service: Variables for Research and Implementation," Library \& Information Science Research 10 (July-September 1988): 331- 335.

2. Jo Bell Whitlatch, "Unobtrusive Studies and the Quality of Academic Library Reference Services," College \& Research Libraries 50 (March 1989): 181-194.

3. Patsy J. Hansel, "Quality Is Not Necessarily Quality: A Challenge to Librarians to Develop Meaningful Standards of Performance for Library Reference Services," North Carolina Libraries 48 (Fall 1990): 184. 4. Rao Aluri, "Improving Reference Service: The Case for Using a Continuous Quality Improvement Method," $R Q 33$ (1994): 220236 .

5. The teaching aspects of reference work are considered implicit in this definition.

6. Jerry D. Campbell, "Shaking the Conceptual Foundations of Reference: A Perspective," Reference Services Review 20 (Winter 1992): 33

7. Paul F. Inglis, "Quality Logistics: A Key Competitive Advantage," Canadian Business Review 19 (Summer 1992): 31.

8. Joan C. Durrance, "Reference Success: Does the 55 Percent Rule Tell the Whole Story?," Library Journal 114 (April 15, 1989): 35.

9. Virginia Massey-Burzio, "Reference Encounters of a Different Kind: A Symposium," Journal of Academic Librarianship 18 (November 1992): 276-280.

10. John Haywood-Farmer, "Anthony Alleyne, Balteano Duffus, and Mark Downing, "Controlling Service Quality," Business Quarterly 50 (Winter 1985/1986): 63.

11. Max Larson, "What Is Going on at Gallup?," (Presentation at a meeting of the Omaha Chapter of the Operations Research Society of America \& the Institute of Management Society, Lincoln, NE, December 2, 1993)

12. Carol C. Kuhlthau, "Inside the Search Process: Information Seeking from the User's Perspective," Journal of the American Society for Information Science 42 (June 1991): 361371

13. George D'Elia and Sandra Walsh, "User Satisfaction with Library Service: A Measure of Public Library Performance?," The Library Quarterly 53 (April 1983): 110-111. 
14. Jacqueline Johnson Brown and Peter $H$. Reingen, "Social Ties and Word-of-Mouth Referral Behavior," Journal of Consumer Research 14 (December 1987): 350-262. See also Paul M. Herr, Frank R. Kardes, and John Kim, "Effects of Word-of-Mouth and ProductAttribute-Diagnosticity Perspective," Journal of Consumer Research 17 (March 1991): 454 462; Marsha L. Richins, "Negative Word-ofMouth by Dissatisfied Consumers: A Pilot Study," Journal of Marketing 47 (Winter 1983): 68-78.

15. J. Joseph Cronin and Steven A. Taylor, "Measuring Service Quality: A Reexamination and Extension," Journal of Marketing 56 (July 1992): 55-68.

16. John A. Goodman, Scott M. Broetzmann, and Colin Adamson, "Ineffective-That's the Problem with Customer Satisfaction Surveys," Quality Progress 25 (May 1992): 35-38.

17. Michele Holleran, "Most Hospitals Measure Satisfaction Incorrectly," Marketing News 26 (September 14, 1992): 4.

18. Thomas Thamara, "Quality Converts Customers into Long-term Partners," Bankers Magazine 173 (September/October 1990): 53. 19. Joan C. Durrance, "Need-Centered Services from the Nebraska Perspective," (Visiting scholar presentation made at the University of Nebraska-Lincoln, March 5, 1993).

20. Ralph Gers and Lillie J. Seward, "Improving Reference Performance: The Results of a Statewide Survey," Library Journal 110 (November 1, 1985): 32-35. See also Crews, "The Accuracy of Reference Service."
21. Charles A. Bunge and Marjorie E. Murfin, "Reference Questions: Data from the Field," $R Q 27$ (Fall 1987): 17-18.

22. Kate Ludeman, "Measuring Skills and Behavior," Training and Development 45 (November 1991): 61-66.

23. Jane P. Kleiner, "Ensuring Quality Reference Desk Service: The Introduction of the Peer Process," $R Q 30$ (Spring 1991): 349 361.

24. Marilyn Domas White, "Evaluation of the Reference Interview," $R Q 25$ (Fall 1985): 76-84.

25. William F. Young, "Methods for Evaluating Reference Desk Performance," $R Q$ 25 (Fall 1985): 69-75.

26. Marjorie E. Murfin and Gary M. Gugelchuk, "Development and Testing of a Reference Transaction Assessment Instrument," College \& Research Libraries 48 (July 1987): 314-338.

27. Arash Afshar, "The Attributive Theory of Quality: A Model for Quality Measurement in Higher Education" (Ph.D. diss., Florida University, 1991)

28. Gwen Arthur, "Customer Service Training for Public Services Staff at Temple University's Central Library System" (Philadelphia, PA: Temple University, April 1990) (ERIC: ED 335042).

29. Durrance, "Reference Success," pp. 3233.

30. Mary Jo Bitner, "Servicescapes: The Impact of Physical Surroundings on Customers and Employees," Journal of Marketing 56 (April 1992): 57-71.
31. Charles A. Bunge, "Potential and Reality at the Reference Desk: Reflections on a 'Return to the Field',' Journal of Academic Librarianship 10 (July 1984): 128-133.

32. William Miller, "What's Wrong with Reference?: Coping with Success and Failure at the Reference Desk," American Libraries 15 (May 1984): 303-306, 321-322.

33. Ralph A. Lowenthal, "Preliminary Indications of the Relationship between Reference Morale and Performance," $R Q 29$ (Spring 1990): 308-393.

34. Ibid

35. Robert Grover, "User Needs: Customizing Services for Your Clients" (Workshop presented at the Nebraska Library Association College \& University and Special \& Institutional Sections joint spring meeting, Lincoln, NE, May 21, 1993). See also Roger C. Greer and Martha L. Hale, "The Community Analysis Process," Public Librarianship: A Reader, edited by Jane Robbins-Carter (Littleton, CO: Libraries Unlimited, 1982), pp. 358- 376 .

36. Anne M. Fredenburg, "Quality Assurance: Establishing a Program for Special Libraries," Special Libraries 79 (Fall 1988): 277-284. 